\title{
La generación de la no pertenencia: La literatura del exilio español en Francia
}

\author{
The generation of not-belonging: The \\ literature of the Spanish exile in France
}

\author{
Rita Rodríguez VARela \\ Hispania, Escuela de español \\ rita.varela@hispania-valencia.com
}

\begin{abstract}
The exile of a large part of the population during the Spanish civil war opened the way for a generation of exiled writers, united by the need to express and give meaning to the experience of trauma. These writers have often been forgotten or relegated to the background because of their difficulty of classification.

This article aims to analyse and delve into the different topics that these authors dealt with in their works, such as the experience of war or exile, the consequences of linguistic duality on their identity, the need to reconstruct family history and in the encounter with writing, a liberating language. Through their Works they gave a new meaning to the concept of frontier, and thus evade traditional classifications.
\end{abstract}

\section{Key-words}

exile, war, identity, language, trauma.

\section{Résumé}

L'exil d'une grande partie de la population pendant la guerre civile espagnole a ouvert une voie à une génération d'écrivains exilés, unis par la nécessité d'exprimer et de donner du sens à une expérience traumatique. Ces auteurs ont souvent été oubliés ou relégués au second plan à cause de la difficulté de classification. Cet article a pour but d'analyser et d'approfondir sur les différents thèmes que ces auteurs abordent dans leurs oeuvres, tels que l'expérience de la guerre ou de l'exil, les conséquences de la dualité linguistique sur leur identité, la nécessité de reconstruire l'histoire familiale et la rencontre avec l'écriture, langage libérateur. À travers leurs oeuvres, ils donnent un nouveau sens au concept de frontière et échappent aux classifications traditionnelles.

\section{Mots-clés}

exil, guerre, identité, langue, trauma. 
Decía Simone Weil (1949) que el sentimiento de arraigo es la necesidad más importante del alma humana y también la más ignorada. Esta sentencia cobra toda su amplitud cuando se piensa a la luz de los traumáticos sucesos que tuvieron lugar en el siglo XX, concretamente, cuando se aplica al fenómeno del exilio.

El 17 de julio de 1936 se sublevaba una parte de la armada española, apoyada por Mussolini, Hitler y Salazar contra el gobierno de la República, provocando el estallido de una guerra cruenta y fratricida que finalizó con el exilio de una gran parte de la población y la instauración de una dictadura que duraría cuarenta años. En el terreno literario las consecuencias fueron la interrupción parcial de las corrientes vanguardistas, la censura y el dominio de la producción, así como el exilio de autores tan destacables como Juan Ramón Jiménez, Rafael Alberti, Jorge Guillén o Pedro Salinas. Es posible hablar de tres grupos muy diferenciados de exiliados españoles durante la guerra civil (Blanco Aguinaga, 2002): en primer lugar, se encontraría la generación de Picasso, Ortega y Gasset y Juan Ramón Giménez, en segundo, la generación del 27; estos dos primeros grupos tienen en común haber consolidado su carrera literaria en España antes del estallido de la guerra. Y un tercer grupo, en el que se incluye la generación de niños y adolescentes del exilio, coetáneo de la llamada en España “generación del 50". En lo que se refiere a este tercer grupo, debe distinguirse, a su vez, entre aquellos que se exilian en países de habla hispana y los que optan por países con un idioma diferente como Francia o Bélgica, pues la cuestión lingüística es un factor diferenciador determinante. Si bien existe un amplio estudio relativo a los escritores exiliados en América, todavía no se ha profundizado tanto en aquellos que optaron por países francófonos y eligieron esa nueva lengua para escribir sus obras. Algunos críticos como Dreyfus-Armand (1994, 1985), Salaüm (1998) o Molina Romero (2003-2004, 2006, 2007) han dedicado tesis y artículos de divulgación científica al estudio de estos autores. Sin embargo, todavía queda mucho camino por recorrer si queremos entender una experiencia tan traumática como es el exilio y evitar la repetición de los errores de nuestra historia europea reciente.

En el corpus literario de escritores exiliados en Francia, se suelen incluir autores como Michel del Castillo, Rodrigo de Zayas, Carlos Semprún-Maura, José Luis de Villalonga, Agustín Gómez Arcos, Jacques Folch-Ribas, Jorge Semprún, Adélaïde Blasquez o Claude Esteban, entre otros. Molina Romero (2007) se refiere a ellos como generación literaria y define sus características generales de la siguiente forma:

Ce sont des enfants en bas âge et de jeunes adolescents qui arrivent en France à la suite d'une situation historique tragique à laquelle ils n'ont pas pris part directement, mais qui va orienter leur vie et leur oeuvre. C'est la génération des enfants de la guerre qui s'acclimatent dans le pays d'accueil et écrivent en français (2007: 120).

No obstante, deberían ser incluidos también en este grupo aquellos escritores pertenecientes a la mal denominada segunda generación, es decir, nacidos en Francia pero de padres 
exiliados. Si bien no han experimentado el exilio desde un punto de vista físico, sí lo han hecho desde una perspectiva interior pues han recibido el exilio como herencia, con todas las consecuencias que ello conlleva.

Todos estos autores se caracterizan por una gran preocupación lingüística, expresada en sus obras a través del uso de los diferentes idiomas, así como por compartir la experiencia del exilio y, con ella, la pérdida de los pilares identitarios sobre los que se sustentaba su ser. En sus novelas, rememoran la infancia y la adolescencia con el objetivo de darle sentido al pasado y todos ellos encuentran en la literatura y en la escritura un nuevo territorio que habitar sin sentirse desplazados y una eficaz herramienta para elaborar el trauma.

Este artículo tiene como objetivo realizar un estudio de los temas comunes que atraviesan las obras de estos autores, víctimas de un mismo conflicto bélico que derivó en el exilio. Se pretende profundizar en la necesidad de contar y de entender lo sucedido a través de la escritura literaria, más allá de las diferencias formales que podrían separarlos. Se espera con ello contribuir al corpus de estudio de una generación que, por su dificultad de clasificación en una literatura nacional concreta, no ha recibido tanta atención como sus contemporáneos exiliados en países latinoamericanos.

El éxodo de unas quinientas mil personas al final de la guerra de España constituye la primera gran migración del siglo XX en Europa. Este éxodo fue precedido de tres años de una guerra civil fratricida que tuvo consecuencias traumáticas en la población. Por ello, se observa que en las obras de los autores de esta generación, la guerra es uno de los temas centrales que conviene abordar. A pesar de que todo el continente estaba viviendo una situación bélica o prebélica complicada, en el caso español hay una gran diferencia, pues se trataba de una lucha entre hermanos. Autores como Jorge Semprún se refieren a ella como "nuestra guerra" (1998), incomparable a ninguna otra; sentimiento que nace del valor simbólico que siempre la acompañó pues se llegó a hablar de ella como de una lucha entre el Bien y el Mal. Si bien todos los autores se refieren a este conflicto a través de los recuerdos de la infancia o de una reflexión sobre las repercusiones que tuvo en su formación identitaria, destaca el caso de Agustín Gómez Arcos. La mayor parte de sus novelas se centran en esa historia reciente de España que le obligó a exiliarse durante el franquismo ante la imposibilidad de seguir viviendo bajo una dictadura. En su primera obra escrita en francés, L'agneau carnivore (1975), siguiendo el hilo de una historia de amor incestuoso entre hermanos, el autor refleja una España sumida en el encierro y en la represión. Asimismo, la España de la dictadura se encuentra como tema vertebral en su obra L'enfant pain (1983), donde desarrolla con un crudo realismo las privaciones que se vivían en un pequeño pueblo durante aquellos años o en Scène de Chasse (furtive) (1978), novela que trata la tortura y la opresión bajo el régimen franquista. Cabe señalar que este es uno de los autores más críticos con la realidad española que, incluso tras la muerte de Franco y la llegada de la democracia, puso de relieve la necesidad de hacer memoria histórica y de no caer en el olvido. Las consecuencias de su incesante trabajo de denuncia fueron una recepción dicotómica: 
La obra exiliada de este neo francés que nunca abandonó su nacionalidad española, es tierna o visceral, conmueve o causa malestar, desprovista de compostura y de prejuicios literarios o de cualquier otra índole. Desde su afrancesamiento hasta su temática, Gómez Arcos incomoda. Su escritura, siempre trasgresora, es a veces entrañable, otras extraña y corrosiva, su crítica mordaz (Molina Romero, 2006: 98).

Tras la guerra, el exilio de estos autores se inaugura con el cruce de una frontera física y continúa con el encuentro de una frontera interior: la barrera de un imaginario social asentado en la presencia de mitos y prejuicios ante el Otro español. A este respecto, señala Edward Said (2001) que es en el imaginario social donde descansa el sentimiento de identidad de una nación, pues los nacionalismos pretenden depositar la verdad en ellos mismos y relegar la mentira a todo lo que se encuentra fuera de ese espacio. Crean barreras para protegerse ante el miedo a lo desconocido, al bárbaro, "son las fronteras de naciones y patrias, las fronteras de religión, partido, sexo o clase social, las barreras que se levantan para proteger lo sagrado, la verdad y el absoluto de herejías, heterodoxias y disidencias" (Aínsa, 1937: 152).

Lo cierto es que el encuentro con el imaginario francés sobre los españoles es otro gran tema que desarrollan los testimonios del exilio español en Francia. Este imaginario surge durante la unión entre Castilla y Aragón en un proyecto imperial que daría a España un gran poder y dominio. Como señala Marín Ruiz (2011), el resto de países europeos encontraron en la mala propaganda una herramienta eficaz para disminuir el poder español, transmitiendo la denominada Leyenda Negra, según la cual, España es "inquisitorial, ignorante, fanática, incapaz de figurar entre los pueblos cultos (...) dispuesta siempre á las represiones violentas; enemiga del progreso y de las innovaciones" (Juderías, 1914: 15). Más allá de la veracidad de lo propagado a través de esta leyenda, esta visión sobre los españoles acompañará al resto de países en algunos casos, teniendo repercusiones en el exilio de la generación de estudio:

\begin{abstract}
Je me souviens aussi qu'un jour où la jeune maîtresse nous racontait l'histoire de Roland, je me reconnus presque fatalement dans le personnage de Ganelon. On ne se privait pas, à l'école comme partout ailleurs, d'évoquer alors avec une certaine complaisance misérabiliste les épisodes calamiteux de l'histoire de France: Alésia, Azincourt ou Sedan. Toujours quelque félonie venait compromettre un dessein héroïque, entraver une aventure exaltante et généreuse - et tout cela, notre maîtresse prenait bien soin de le souligner, par l'entremise d'une main étrangère, d'un effroyable complot que les pays voisins machinaient contre la nation française (Esteban, 1990: 47).
\end{abstract}

En esta misma línea, célebre y conocido es el episodio de xenofobia sufrido por Jorge Semprún cuando intenta comprar en una pastelería parisina y es puesto en evidencia a causa de su pésima pronunciación de la lengua francesa. La pastelera se burla de los españoles que, según ella, se dedican a invadir Francia sin dignarse a aprender el idioma. Semprún señala atónito que incluso se aludió a l'armée en déroute, desencadenando el recuerdo del poema Après la bataille (1859) de Victor Hugo, en el que se narra como un español descarga su 
arma contra su padre aprovechándose de la piedad que le había concedido, es decir, la visión del español como un traidor: "l’homme, une espèce de Maure" (Semprún, 1998: 63). Posteriormente, con la llegada del Romanticismo, la mirada que el extranjero dirige a España está marcada por el idealismo de los viajeros románticos que acuden a ella buscando su exotismo. Este nuevo estereotipo se unirá a la visión anterior dando lugar al tópico de la "España de pandereta", un país sumido en el atraso y en la devoción cristiana, habitado por hombres orgullosos y mujeres peligrosas que gozan en su tiempo libre de prácticas tan salvajes como los toros. Esta mezcla de diferentes épocas aparece perfectamente condensada en la obra L'Exil est mon pays (2006) de Isabelle Alonso, cuando relata el tipo de bromas a las que tenía que enfrentarse su padre y como este, lejos de sentirse humillado, les seguía la corriente para sacar a relucir su ignorancia:

Des blagues de ses compagnons de circonstance. Angel en avait entendu d'autres à l'armée, mais ce genre d'humour ne le faisait tout simplement pas rire, pas sourire même. Quand ils le questionnaient sur sa vie, Angel se vengeait. Comment elle est ta femme? Elle est belle, très belle. Elle danse le flamenco? Bien sûr que oui. Tous les matins elle met ses castagnettes, sa robe à pois, et elle se lance dans des pirouettes et des zapateados jusqu'à l'heure du repas. Et t'as déjà vu une corrida? Non seulement j'ai vu une corrida, mais on a un taureau à la maison, qui s'appelle Paquito, et tous les soirs faut le sortir pisser, une craie corvée. Tu te foutrais pas un peu de nous? Pas mon genre. T'as qu'à nous faire la voir ta femme, t'as bien une photo? Bien sûr que j'ai une photo, mais je ne vous la montrerai jamais, nous les Espagnols on est très jaloux. Si tu voyais ma femme, je serais obligé de te tuer, c'est comme ça, c'est la coutume (Alonso, 2006: 27).

Junto a los prejuicios provenientes de los tópicos que han circulado a lo largo de la historia tanto francesa como española, pues también en España existían estereotipos sobre Francia, Semprún reflexiona sobre otro aspecto sumamente revelador, el enfrentamiento con la mirada del otro:

Ils nous voyaient comme des rouges espagnols, ces estivants, et cela nous étonnait, au premier abord, cela nous dépassait, et pourtant ils avaient raison, nous étions des rouges espagnols, j'étais déjà un rouge espagnol sans le savoir, et Dieu merci, ce n'est pas mal du tout d'être un rouge espagnol (1963: 154-155).

Durante este episodio, el joven exiliado parece vivir una especie de anagnórisis, pues se percata de un elemento muy significativo que había pasado por alto: su nueva condición de rojo español exiliado. En este sentido, Sartre señala que el hecho de ser visto a través de otros ojos, el choque con la mirada del Otro, "est d'abord un intermédiaire qui renvoie de moi à moi-même" (1981: 305); es gracias a esa proyección que el sujeto se descubre. Semprún se reconoce en el Otro español a través de la confrontación con el Otro francés. Como se observa en sus palabras, este descubrimiento es calificado positivamente por el escritor, quien 
siempre llevó su condición de exiliado y de republicano español con gran orgullo. Si el exilio es un castigo destinado a arrebatar al sujeto no solamente todo lo que tiene, sino también todo lo que es; esta materialización de una pérdida política e ideológica es contrarrestada por el sentimiento de poseer la verdad y por el orgullo de su defensa. En palabras de Arrieta, "el exiliado es un ser abatido con dignidad y con orgullo, porque se siente en toda circunstancia arropado por la razón y por la verdad" (2013: 165).

Ineludiblemente relacionada con la identidad, se encuentra la cuestión lingüística. Es necesario tener presente que esta generación no siente la lengua francesa como una lengua de adopción o impuesta sino que la sienten como suya. Se trata de un idioma que los ha acompañado en una de las andaduras más complicada de sus vidas: la pérdida violenta de la tierra natal y su consecuente exilio. Junto a ella han experimentado la otredad y la exclusión pero, paralelamente, con ella se han formado, han superado las adversidades y se han hecho más fuertes. Para muchos autores, la lengua francesa es la lengua de la conquista, a través de su apropiación toman el mando de su exilio y de su nueva vida: “j'avais le goût de l'exigence. J'ai trouvé mon compte dans cette langue française. C'était aussi l'endroit où je plongerais des racines que je n'avais pas" (Blasquez, 1999: 271). En el caso concreto de Adelaïde Blasquez, la conquista de la lengua francesa conlleva también la liberación del yugo materno. Esta autora tenía una madre dominadora y exigente que, a pesar de ser alemana, la obligaba a hablar español y le prohibía el francés: "être libre. Et pour ce faire, fuir à tout jamais les touffeurs du ghetto maternel, ne permettre à rien ni personne de déterminer mon destin à ma place, habiter mon nom" (Blasquez, 1999: 202). El nombre propio, en tanto representación de la identidad, suele ser un medio de apropiación cultural. Muchos de estos autores decidieron afrancesar sus nombres, como es el caso aquí de Emma Adela Martin Fischer que cambió su nombre por el de Adélaïde y relegó cualquier relación materna por el apellido Blázquez de su abuela paterna, que también afrancesó en Blasquez. Igualmente, Miguel Janicot del Castillo se convertirá en Michel del Castillo y otros autores, como Jorge Semprún, jugarán con diferentes pronunciaciones para crear ambigüedad.

En lo que se refiere a la relación y el sentimiento que estos autores mantienen con la lengua española, se observa que varía, oscilando desde el amor incondicional, en tanto representación del paraíso perdido, hasta el odio y el rechazo, en tanto barrera y lastre que les impide inscribirse totalmente en el nuevo territorio, acentuando continuamente su condición de extranjeros.

En lo que respecta al sentimiento de la lengua española como "langue de la discorde" (Molina, 2007), destaca el caso de Michel del Castillo para quien el español es sinónimo de abandono y tristeza. El autor llega a calificar a España como una enfermedad que lo ha perseguido toda su vida: "Je ne peux concevoir l'Espagne détachée de moi-même; je ne saurais non plus en parler comme le ferait un pur Espagnol [...] Toujours j'ai souffert de l'Espagne comme d'une maladie" (Castillo, 1996: 28). El rechazo a España no se realiza únicamente 
desde una perspectiva actual, sino que estos autores realizan una búsqueda minuciosa en la historia de España, valiéndose de ciertos episodios del pasado para mostrar un país cruel, sumido en el oscurantismo católico. Se enmarca en esta corriente la obra La Brigue et le talion (1996) de Rodrigo de Zayas, definida como un "cri de douleur et de courage des Arabes expulsés et massacrés par l'Espagne catholique" (Molina, 2003-2004: 161). Zayas retrata un país marcado por la intolerancia y habitado por un pueblo incapaz de reaccionar y aprender de los errores. Estancado, nunca ha hecho un ejercicio de memoria histórica y por tanto se ve abocado a la repetición de lo mismo en diferentes contextos:

Hegel avait raison, l'Histoire se répète. L'Histoire d'Espagne exagère, elle bégaye! $1492,1521,1525,1548,1571,1588,1609,1808,1898,1936$, j'en passe et des meilleures. Toujours le menu peuple contre des soldats professionnels mieux armés, mieux entraînés (Zayas, 1996: 72-73).

Lo cierto es que a través de esta enumeración de fechas marcadas por la repetición de una misma historia, o mejor dicho, de una misma esencia, el escritor señala indirectamente la continuidad, pues también durante la guerra civil española se volvió a encontrar la situación a la que hace referencia bajo la denominación del repetitivo menú de un pueblo luchando por sus derechos contra soldados que los superan en todos los sentidos. En esta misma línea pero más explícito resulta Michel del Castillo cuando señala la continuidad desde los tiempos de Felipe II hasta los de Franco: "la même indifférence hautaine, une identique impassibilité, une mélancolie similaire" (Castillo, 1997: 200-201).

En otras ocasiones, encontramos que la lengua española ha sido politizada y es el devenir de la historia y el desenlace de la guerra el que provoca el sentimiento de rechazo. Se encuentran en esta situación aquellos autores para quienes la lengua natal se ha convertido en la lengua de la censura, en una lengua prohibida y dominada por el pensamiento franquista:

Je n'ai pas trahi la langue espagnole. Je me sens maintenant beaucoup plus riche qu'avant, puisque, le cas échéant, je peux écrire les deux, et le français et l'espagnol. Mais il est arrivé un moment où la langue espagnole n'était plus ma langue: c'était la langue du franquisme, et donc je ne pouvais pas m'exprimer avec. [...] Elle appartenait à un régime, il fallait écrire comme le régime le voulait. Donc c'était un outil pour le régime, mais pas pour l'écrivain. Ou du moins, elle a cessé d'être un outil pour moi (Gómez Arcos en Kohut, 1983: 130).

Frente a una lengua dominada que arrastra consigo una historia trágica, la lengua francesa se presenta como una especie de lienzo en blanco, un idioma nuevo y sin memoria que ofrece al escritor otro comienzo o por lo menos una continuidad.

No obstante, en la mayor parte de los casos, esos sentimientos de rechazo van evolucionando a medida que avanza la búsqueda iniciada a través de la escritura. Esta evolución se encuentra concienzudamente expresada en la obra Le partage des mots (1990) de Claude 
Esteban, periplo identitario expresado en un concienzudo testimonio lingüístico. El autor relata su imposibilidad inicial para aceptar la arbitrariedad del signo y como esa negación le dificultaba aceptar la presencia de dos idiomas que desdoblaban la realidad constantemente. Se trata de la narración del dolor de un trauma causado por la escisión entre el lenguaje y la realidad. Este sentimiento se tradujo en el intento de ignorar una parte esencial de su ser y en el alejamiento de su padre, portador de la lengua y la cultura española en su casa, llegando a convertirlos en dos extraños. No será hasta su estancia en Tánger, lugar sentido por el autor como un idílico Babel, que podrá entender la esencia de las lenguas y su posibilidad de convivencia en perfecta armonía. Y lo más importante, dejándose llevar por una deriva de reflexión interior, encontrará la poesía, lenguaje liberador. A lo largo de toda su carrera, su actividad estará marcada por la convivencia de varias lenguas: poeta francés, profesor de español en la Universidad de París, traductor al francés de diversos poetas franceses, crítico de arte, Claude Esteban ha sabido conjugar sus dos idiomas en una sinergia expresiva inagotable. Lo cierto es que estos escritores asocian diferentes sentimientos y parcelas de su ser a cada lengua y se caracterizan por haber encontrado la forma de convivir con la dualidad. Así, en una entrevista, Adélaïde Blasquez (1976) reflexionaba sobre el papel de cada lengua en su vida, señalando que sería incapaz de escribir una obra en español por su falta de dominio, siendo el francés su lengua de escritura y de pensamiento. El francés es, para ella, la lengua de las ideas, el idioma racional; el español, en cambio, es un idioma orgánico, de los instintos. Otros autores como Isabelle Alonso hacen una asociación entre lengua y espacio. El español, lengua del interior, segura y protectora, representa el universo familiar y la ternura, mientras que el francés, la lengua del exterior, representa las vicisitudes del día a día, es una lengua para protegerse en la vida social, "une langue un peu sèche, presque hostile, comme une arme pour se défendre” (Alonso, 2006: 75). Más compleja es la relación de Jorge Semprún con los diferentes idiomas que domina, así en una entrevista explicaba que "cuando estoy en Madrid, pienso y hablo en castellano, cuando estoy en París en francés. Y si estoy algunas semanas seguida en Berlín pienso en alemán" (24/9/2003). Lo cierto es que el autor atravesó diferentes fases en su relación con las lenguas. La lengua francesa, se presenta en un primer momento como la lengua del exilio y del rechazo al Otro extranjero, y la lengua española, como una traición que delata y expone continuamente su condición de diferente. Al contrario de lo que ocurría con Claude Esteban, Semprún no quiere negar sus orígenes, sino protegerlos de la banalización:

Je n'ai pas envie de lui expliquer pourquoi je parle tout à fait comme eux, pourquoi je parle comme le Commandant, sans accent, c'est-à-dire, avec un accent bien de chez eux. C'est le plus sûr moyen de préserver ma qualité d'étranger, à laquelle je tiens pardessus tout. Si j'avais de l'accent, ma qualité d'étranger, serait dévoilée à tout moment, dans toute circonstance. Elle deviendrait quelque chose de banal, d'extériorisé. Moimême, je m'habituerais à cette banalité d'être pris pour un étranger. Du même coup, ce ne serait plus rien, d'être étranger, cela n'aurait plus de signification. C'est pour cela 
que je n'ai pas d'accent, que j'ai effacé toute possibilité d'être pris pour un étranger, d'après mon langage. Être étranger, c'est devenu en quelque sorte une vertu intérieure (Semprún, 1963: 119).

Semprún pretende crear un escudo protector, preservar sus orígenes, y apropiarse de esa nueva cultura del país en el que reside y, con ella, de su destino. Como señala el psicoanálisis, la vivencia de una experiencia traumática como es el exilio provoca la fragmentación del sujeto, el cual debe enfrentarse, por un lado, a una pulsión violenta que debe canalizar creativamente y, por otro, al bloqueo de dicha fragmentación gracias a una afirmación narcisista y a una redefinición del objeto. A este respecto, la lengua española ocupa el lugar de la violencia pulsional, se relaciona con el grito y la cólera, sentimientos idóneos, según el autor, para el español por su tendencia al barroquismo y a la amplificación dramática. Mientras que el francés, por su claridad y precisión racional, sublima esas pulsiones insatisfechas convirtiéndose en una especie de segunda piel protectora:

J'avais besoin de cette clarté comme on a, assoiffé, après une longue marche épuisante, besoin d'une eau de source. J'avais besoin de cette langue qui, apparemment, coulait de source, mais dont la limpidité était le résultat d'un exigeant travail sur l'inertie et l'opacité naturelles du langage (Semprún, 1998: 132).

Por lo tanto, como se puede observar, los autores de esta generación, tras un periodo de adaptación, de silencio o de rechazo, encuentran la forma de convivir con la dualidad cultural y lingüística que los habita. Incluso en casos tan extremos como el de Michel del Castillo citado anteriormente, al final no pueden negar totalmente esa parte ineludible de su ser. En una entrevista realizada por el periódico El País a propósito del premio Renaudot que recibió en 1981, el autor confesaba su necesidad, al menos física, de volver a España frecuentemente: "necesito ir a España con frecuencia. Es una necesidad física. Intelectualmente, digamos que soy más afín a la cultura francesa; pero España me falta en otros aspectos y, cuando dejo mucho tiempo sin visitarla, me siento desgraciado" (Fidalgo, 17/11/1981).

Otro de los elementos que ocupan gran parte de la obra de estos autores, es la propia literatura. El sentimiento de extrañamiento y desarraigo producido por la aparición de un nuevo país con una nueva lengua, encuentra un sustento en este arte. La literatura ocupa un papel central, ya sea como expresión de un sentimiento, como metáfora de una realidad cíclicamente repetida o, incluso, como apoyo moral y refugio. Encuentran en las páginas de escritores franceses y españoles un soporte, una ayuda para sobrevivir y, en ocasiones, se podría hablar de un nuevo territorio que habitar:

J'étais sorti de la guerre de mon enfance pour entrer dans la guerre de mon adolescence, avec une légère halte au milieu d'une montagne de livres. J'étais à l'aise devant n'importe quel livre, devant n'importe quelle théorie. Mais dans les restaurants, les serveurs ne voyaient jamais mes gestes d'appel; dans les magasins, je devais devenir invi- 
sible, les vendeuses ne réalisent jamais ma présence. Et les téléphones ne m'obéissaient pas, je tombais toujours sur un faux numéro (Semprún, 1998: 103-104).

Se trata de una forma de arte que les abre nuevas posibilidades y horizontes, "en lisant, je fuyais la vie 'inviable', celle de la guerre et du crime, celle de la peur et de la trahison" (Castillo, 1995b: 67). En las historias llenas de fantasía, de ogros y lobos, el terror de la vida real se vuelve un poco más soportable. La literatura es un refugio en el que impera la sensación de protección y de unión espiritual con los escritores, tanto es así que llegan a dirigirse a ellos, afirmando, en el caso de Michel del Castillo y su encuentro con la obra de Dostoievski, que "nous n'avons jamais lu pour fuir: nous lisions pour respirer" (1995b: 100). Este sentimiento de unión es denominado como un "compagnonnage spirituel" (1990: 155) por Claude Esteban. El poeta, que había construido una muralla durante su infancia para protegerse y nunca mostraba sus sentimientos ni compartía sus pensamientos, con los escritores de sus lecturas se permitía incluso los sentimientos más ingenuos, convencido de que lo escuchaban y comprendían, llegando a referirse a Nerval y a Baudelaire como "frères d'infortune" (1990: 156). Análogamente, al igual que ocurría con la elección del idioma, se observa una distinción entre los sentimientos asociados a cada tipo de literatura. En muchas ocasiones, la francesa es considerada como la literatura gracias a la cual estos autores se recomponen; los acompaña en esta nueva tierra del exilio en la que deben construir o reconstruir su identidad:

La boulangère du boulevard Saint-Michel me chassait de la communauté, André Gide m'y réintégrait subrepticement. Dans la lumière de cette prose qui m'était offerte, je franchissais clandestinement les frontières d'une terre d'asile probable. C'est dans l'universalité de cette langue que je me réfugiais. André Gide, dans Paludes, me rendait accessible, dans la transparente densité de sa prose, cet universalisme (1998: 133-134).

La literatura española está íntimamente conectada con la parte más pulsional, con las raíces perdidas y una historia común llena de dolor. Se trata del arte del desengaño, palabra difícil de traducir, de ese “appel ombreux chez Quevedo, lorsqu'il avait forcé la syntaxe de sa langue à exprimer en une ligne étonnante le harassement de l'Être à travers le temps: 'Soy un fue, un será y un es cansado"” (Esteban, 1990: 127). Claude Esteban encuentra en la literatura española la forma de romper la muralla que se había creado, vuelve a reencontrarse con sus raíces españolas gracias a un encuentro accidental con las primeras líneas del Quijote, las cuales le hacen percibir "une mystérieuse musique dont tout ou presque m'échappait, mais dont la mélodie, au fil des mots que je déchiffrais, exerçait un attrait difficilement analysable" (1990: 79).

Otro punto ineludible en el estudio de estos autores es la cuestión del trauma pues el exilio es una experiencia traumática que tiene graves consecuencias psicológicas en el sujeto que lo experimenta. Se trata de un "traumatismo acumulativo o de tensión" (León 
y Rebeca Grinberg, 1984: 24) que tiene efectos desubjetivizantes pues, como se ha visto en anteriores puntos, se produce una pérdida identitaria y lingüística, con su consecuente enfrentamiento a una nueva tierra, lengua y sociedad en muchas ocasiones hostil. Para el ser exiliado, el eje espacio-temporal se encuentra paralizado y es inseguro porque "el exilio es esa indeseable pero obligada situación en la cual quienes lo viven se confrontan con el pasado, dudan del presente y perciben un saber de incertidumbre hacia el futuro" (Gamboa, 2003: 41). La simbología de la escisión interior y de la esquizofrenia lingüístico-cultural es un motivo constante en sus obras que muestra la problematicidad identitaria que experimentan. En el caso concreto de aquellos exiliados que, como nuestros autores, no solo han cambiado de país sino también de lengua, este cambio se presenta siempre como traumático, al menos en su primera fase. El sujeto debe luchar para encontrar la manera de convivir con los diferentes idiomas sin que ello sea asociado a la negación o traición de una parte esencial de ellos mismos ni provoque una desestabilización constante de su identidad. A este respecto, Alexis Nuselovici (2013) explica que la pérdida de la lengua natal inaugura en el sujeto su primera conciencia del exilio, culminando con la adquisición del idioma del país de acogida que abre el denominado post-exilio "mélange de familiarité et d'étrangeté qui distingue cette expérience" (2013: 30). En este contexto, se observa que los autores de nuestro estudio encuentran en el proceso de escritura una herramienta indispensable para elaborar el trauma. Escribir, narrar lo sucedido ayuda a entender y a salir de la repetición incesante de lo mismo, "mediante la elaboración el sujeto logra salir del lugar coagulado de lo irrepresentable y vincularse de otra manera con eso que conmocionó su ser, integrándolo a su historia de vida" (Asselborn, 2013: 37).

En muchas ocasiones, el proceso de escritura aparece representado como una especie de cura y condena. Si por un lado es una herramienta que permite canalizar las pulsiones y dar sentido a una situación traumática, por otro lado es también una especie de adicción que los obliga a escribir y reescribir incesantemente y, por tanto, revivir lo sucedido. Michel del Castillo afirma que para existir “j’étais condamné à écrire et, même, à récrire sans fin" (1995: 16) y Jorge Semprún se cuestiona en un primer momento las consecuencias de empezar el relato de lo vivido, teniendo que elegir entre la escritura o la vida: "escribir me mantiene en la memoria de la muerte, que para escribir tengo que estar todo el tiempo recapacitando, volviendo a sumergirme en aquella memoria" (Semprún en Vilanova, 2006: 111) Una memoria que el escritor califica de "literalmente mortífera", escribir conlleva encerrarse en la experiencia de la muerte y encuentra en la política una vía posible para canalizar el dolor del trauma. No será hasta su desengaño con el mundo de la política y su encuentro con Manuel Azaustre que el autor comience su carrera literaria movido por la necesidad de entender y de hacer entender experiencias tan traumáticas como los campos de concentración nazis, el exilio durante su juventud o la tortura por la Gestapo. 
Las obras de estos autores forman parte de una exploración interior; constituye un periplo identitario en el que se sumergen interrogando e interrogándose. En el momento en que se cruza una frontera, se produce un cambio, trágico y violento en este caso, que obliga a plantearse aquello que se era y se ha perdido, pues "traspasada la línea divisoria, el sentimiento de identidad en cuanto pertenencia y permanencia se trunca" (Alted, 2004: 246). En el caso de Claude Esteban, esta nueva tierra identitaria es la poesía, pues en ella la lengua deja de ser un elemento traumático y delimitador, ya que posee un idioma y una forma de expresión propia. La poesía se sitúa en el límite entre la realidad y el sueño, el pasado y el futuro, de tal modo que abre nuevos caminos de creación y comprensión. El poeta habita la obra, despojándose de cualquier problema territorial, "se situe au moment, d'une surprise, induite dans un temps et un espace non définis. Une surprise qui ne trouve d'aboutissement et de finalité que dans la création. En l'occurrence le poème" (Zimbris, 2010: 2). La palabra poética escapa a la limitación geográfica, crea a través del acto de nombrar; con ella, el poeta vuelve a renacer, a vivir y a experimentar lo arrebatado:

Je n'avais presque pas eu d'enfance; la poésie me proposait d'en vivre une autre, d'être à nouveau cette créature qui balbutie, qui découvre à la fois les mots et le monde, mais non plus dans l'insouciance de la nature; dans la gravité et dans la conscience d'un destin (Esteban, 1990: 145).

Más problemático y complejo es el caso de aquellos niños, hijos de exiliados, que nacieron en Francia y por tanto se sienten franceses de pleno derecho pero deben enfrentarse a la extranjería y al exilio como herencia. A este respecto, Isabelle Alonso realiza una esclarecedora reflexión cuando señala "nous, leurs enfants, sommes nés étrangers. Car l'étrangeté, c'est héréditaire" (2006: 64). Estos extranjeros por herencia, reciben el nombre de exiliados de la segunda generación, como si fuera una especie de segunda remesa, pero en su propia denominación se encuentra ya la esencia de la incomprensión hacia ellos. Mientras que los padres tienen unos orígenes definidos y una tierra propia, temporalmente negada, a la que podrán volver, sus hijos viven en su tierra de nacimiento pero no pueden considerarla como propia. Como consecuencia, viven sumidos en una búsqueda identitaria obsesiva y difícil de concluir, "no saben dónde ubicarse, se debaten entre la necesidad de seguir una línea marcada por la historia familiar y la urgencia de entrar en el molde de la sociedad en la que han nacido" (Hadj, 2008: 38). Sus mundos y sus identidades se encuentran desdoblados entre dos formas de ver una misma realidad. Paradójicamente, la pertenencia a dos países, les niega un territorio en el que poder inscribirse, arrojándolos al espacio de la no pertenencia, "on peut affirmer qu'ils sont à la fois des enfants de deux sociétés et des enfants de nulle part. Leur véritable patrie est l'exil" (Bolzman, 1996: 231). De hecho, tampoco la vuelta a España resulta resolutiva, pues en realidad es un país desconocido e idealizado en el que nunca habían vivido por lo que vuelve a trasladarlos al punto de inicio. Isabelle Alonso (2006) explica como 
en su primer viaje a España descubrió que su pronunciación de las erres y zetas, así como algunas expresiones que empleaba, desvelaban su extranjería, por lo que si era una extranjera española en Francia, era igualmente una extranjera francesa en España. En este mismo sentido, Blasquez mostraba los mismos sentimientos de extrañeza en cualquier territorio:

No consigo superar el hecho de ser española y, en realidad, me siento extranjera cuando estoy con los españoles, porque nunca viví en España y la España que me fabriqué es completamente irreal, pero me siento completamente extranjera también con los franceses (Blasquez, 1976: 50-51).

Frente a este sentimiento de desarraigo, la escritura ofrece una posibilidad de creación de nuevos espacios en los que las fronteras se diluyen y el nexo que los une es la historia de una pérdida, de una derrota injusta:

Apatrides, cosmopolites, persécutés, expulsés, arrachés, déracinés, émigrés, réfugiés, transplantés, greffés, rejetés, assimilés, intégrés, disparus... Je marche aux côtés de tous les vaincus de la terre, chassés par les caïns éternels sur les routes sans fin de la défaite. Ces routes, je n'y ai jamais mis les pieds et quiconque m'observerait, déambulant dans une rue parisienne, humant l'air du temps, guettant d'un oeil expert les nouveautés de boutiques, ne verrait qu'une bourgeoise en goguette et un exemple encourageant d'intégration réussie. Les escadrons de l'exil qui campent la nuit de mon esprit ne sont pas visibles à l'oeil nue. J'ai passé des années à les cacher pour faire semblant d'être comme tout le monde. Mais moi je suis du pays des étrangers. Des exilés. Les miens. L'exil est mon pays (Alonso, 2006: 297).

La identidad y las raíces se convierten de esta forma en una virtud interior, como buscaba Jorge Semprún, en una forma de comportarse y de actuar ante la vida. Se abre un nuevo espacio en el que la escritura es el motor que empuja constantemente al exiliado a crearse y recrearse de nuevas formas.

Otra de las características más importantes que comparten estos hijos o, incluso a veces, nietos de los exiliados, es la necesidad de rastrear esa herencia, buscando y recomponiendo la historia familiar, ya sea de una forma biográfica o fantástica. En el caso de Isabelle Alonso, tras L'Exil est mon pays (2006), primera obra alejada de su hasta entonces habitual temática feminista, la escritora se sumergirá en la historia de su familia en diferentes contextos. En Je mourrai une autre fois (2016), aparece relatada la historia de su padre, su infancia y juventud, el nacimiento de sus ideales, su compromiso político y también el amor. Posteriormente, con Je peux me passer de l'aube (2017), siguiendo con el mismo protagonista, profundizará con más detalle en temas como los campos de concentración, los sentimientos de derrota y la situación económica y social del país tras la guerra. Igualmente interesante es su obra Fille de rouge (2009) en la que la autora se centra esta vez en la figura materna, relatando la niñez y juventud bajo el estallido de la guerra, el exilio y su posterior vida en Francia. Sumidas en esta misma reconstrucción de la historia, se encuentran obras de otros 
autores como Mille ans après la guerre (2017) de Carine Fernández, historia de un regreso a una tierra natal que ya no existe y rememoración de sucesos como las cárceles políticas, los campos de concentración o el exilio; así como Dans l'ombre du viaduc (2017) de Alain Delmas, en la que encontramos a un joven que viaja a la tierra de su padre, provocando el resurgimiento de los recuerdos y del dolor de la guerra.

Expulsados, exilados, discriminados, olvidados, como se ha visto, estos autores comparten una historia marcada por el dolor y la pérdida. Si el exilio es una experiencia traumática que cambia la vida y la identidad del sujeto para siempre, la literatura del exilio es ese nuevo territorio donde cohabitan no solo diferentes idiomas, sino también diferentes formas de decirse y sentirse. Los autores de esta generación, comparten una relación con el mundo y el lenguaje basada en la alteridad, por lo que luchan para conseguir preservar su autenticidad y adecuar su dualidad en un contexto complejo y, a menudo, hostil. A través de una expresión plurilingüe, negocian con sus pulsiones elaborando el trauma y resolviendo la inadecuación de su ser. En este sentido, George Steiner hablaba de un nuevo concepto de escritor, sabio de la lingüística, que evade el reduccionismo nacional, pues le corresponde el mundo. Su hogar se caracteriza por un incesante movimiento, con lo cual "sugieren que la literatura moderna puede ser considerada como una estrategia de exilio permanente. El artista y el escritor son turistas infatigables que miran los escaparates en los que se exhibe toda la gama de las formas existentes" (1973: 30). A través de la creación de nuevos espacios alejados de una dialéctica reductora, se inaugura un nuevo espacio en el que mente y cuerpo se revelan, transmiten el ser en el mundo. Con ellos, el leguaje adquiere ese significado comunitario al que alude Jorge Semprún cuando lo elige como su patria: "c'est-à-dire un espace de communication sociale, d'invention linguistique: une possibilité de représentation de l'univers. De le modifier aussi' (1995: 77). Y dicha modificación de las representaciones y de los espacios de la sociedad, la inician estos autores a través de sus obras, al concebirlas como una frontera infinitamente transgredida y, por ello, enriquecedora.

En este contexto, es posible afirmar que a pesar de las diferencias de estilo y forma, las obras de estos autores tienen una conexión más profunda: la expresión de una experiencia traumática y la necesidad de darle un sentido. Asimismo, exponen y denuncian sucesos reales dando, con ello, voz a los silenciados y pretendiendo evitar su repetición. Realizan un esfuerzo por poner en discurso acontecimientos marcados por su indecibilidad y donde la discursivización tiene un valor terapéutico en el autor así como en el receptor. La literatura del exilio es un nuevo espacio, una nueva patria cultural que unifica y crea nexos entre una comunidad con una historia común, más allá de su origen. Se trata de un espacio emocional, despojado de fronteras. 
Anales de Filología Francesa, n. ${ }^{\circ}$ 28, 2020

Rita RodríGuez VARELA

\section{Referencias bibliográficas}

AínSA, Fernando. 1937. Espacio literario y fronteras de la identidad. San José, Editorial de la Universidad de Costa Rica.

Alonso, Isabelle. 2006. L'Exil est mon pays. Paris, Héloïse d'Ormesson.

Alonso, Isabelle. 2009. Fille de rouge. Paris, Héloïse d'Ormesson.

Alonso, Isabelle. 2016. Je mourrai une autre fois. Paris, Héloïse d'Ormesson.

Alonso, Isabelle. 2017. Je peux me passer de l'aube. Paris, Héloïse d'Ormesson.

Alted Virgil, Alicia. 2004. "Exilio, identidad y alteridad" in Suárez, Alfaro, Bénit, Martínez, Mata y Tejedor (eds.). L'Autre et soi-même. La identidad y la alteridad en el ámbito Francés y Francófono. Madrid, Ibérica Asistencia, 245-261.

ArrietA, J A A . 2013. "Exilio y emigración: De la experiencia del emigrante al compromiso del exiliado. Amado Alonso y Ramón de Belausteguigoitia" in El exilio literario de 1939, 70 años después, Actas, 163-164. Universidad de la Rioja.

Asselborn, Adriana Leonor. 2013. La angustia ante la ausencia de elaboración psíquica de vivencias primarias traumáticas. Tesis de Licenciatura, Universidad Católica Argentina, Facultad Teresa de Ávila.

Blanco Aguinaga, Carlos. 2002. "La literatura del exilio en su historia" in Migraciones y exilios: Cuadernos de la Asociación para el estudio de los exilios y migraciones ibéricos contemporáneos, $\mathrm{n}^{\circ} 3,23-42$.

Blasquez, Adélaïde. 1976. “Adelaida Blázquez: raíces y liberación” in Triunfo, №721, 5051.

Blasquez, Adélaïde. 1999. Le bel exil. Paris, Grasset.

Bolzman, Claudio. 2012. "Elementos para una aproximación teórica al exilio" in Revista andaluza de antropología, n⿳3 3, Migraciones en la globalización, 7-30.

Castillo, Michel del. 1995. Tanguy. Paris, Gallimard.

Castillo, Michel del. 1995b. Mon frère l'idiot. Paris, Arthème Fayard.

Castillo, Michel del. 1996. Le Sortilège espagnol. Paris, Gallimard.

Castillo, Michel del. 1997. La Tunique d'infamie. Paris, Arthème Fayard.

Delmas, Alain. 2017. Dans l'ombre du viaduc. Paris, Éditions Intervalles.

Esteban, Claude. 1990. Le partage des mots. Paris, Gallimard.

Fernández, Carine. 2017. Mille ans après la guerre. Paris, Éditions Les Escales.

FIDALGo, Feliciano. 1981. "El escritor francés de origen español, Michel del Castillo, 
Anales de Filología Francesa, n. ${ }^{\circ}$ 28, 2020

LA GENERACIÓN DE LA NO PERTENENCIA: LA LITERATURA DEL EXILIO ESPAÑOl EN FrANCIA

premio Renaudot 1981" in El País, Cultura. <https:/elpais.com/diario/1981/11/17/cultura/374799601_850215.html> [21/04/20].

GamboA, José. 2003. La lengua después del exilio. Influencias suecas en retornados chilenos. Suecia, Umea.

Gómez Arcos, Agustín. 1975. L’Agneau Carnivore. Paris, Stock.

Gómez Arcos, Agustín. 1978. Scène de Chasse (furtive). Paris, Stock.

Gómez Arcos, Agustín. 1983. L’énfant pain. Paris, Seuil.

Grinberg, Rebeca, Grinberg, Leon. 1984. Psicoanálisis de la migración y del exilio. Madrid, Alianza Editorial.

HADJ HANDRI, Nathalie. 2008. "La identidad mutante. La construcción de la identidad en los hijos de inmigrantes" in Revista de documentación social, nº151, Cáritas, 35-48.

Hugo, Víctor. 1859. La légende des siècles. Paris, Édition Hugues.

JUDERÍAs, Julián. 1914. La leyenda negra y la verdad histórica. Madrid, Editora Nacional.

Kohut, Karl. 1983. Escribir en París. Entrevistas con Fernando Arrabal, Adela de Blasquez, Jose Corrales Egea, Julio Cortazar, Agustin Gomez Arcos, Juan Goytisolo, Augusto Roa Bastos, Severo Sarduy y Jorge Semprún. Barcelona, Hogar del libro.

Marín Ruíz, Ricardo. 2011. Tres visiones de España durante la guerra civil. Murcia, Nausícaä.

Molina Romero, Carmen. 2003-2004. "Voix en exil, voix en français" in Cuadernos de Investigación filológica, tomo 29-30, 159-175.

Molina Romero, Carmen. 2006. “Agustín Gómez Arcos: la aventura de una escritura franca” in Logosphère: revista de estudios lingüísticos y literarios, n², 91-104.

Molina Romero, Carmen. 2007. "Écrivains afrancesados au XXe siècle" in Gasquet, Axel \& Suárez, Modesta (dir.). Écrivains multilingües et écriture métisses. L'hospitalité des langues. Clermont-Ferrand, Presses Universitaires Blaise Pascal, 231-244.

Nuselovici, Alexis. 2013. "Expérience et écriture du post-exil" in Ouellet, Pierre (ed.). Le soi et l'autre: l'énonciation de l'identité dans les contextes interculturels. Québec, Les presses de l'Université Laval, 23-33.

SAID, Edward. 2001. Reflections on Exile. Harvard Univeristy Press.

SALAÜM, Serge. 1998. "El exilio literario en Francia: el Boletín de la Unión de Intelectuales Españoles" in Aznar Soler (ed.). El exilio literario español de 1939. Actas del Primer Congreso Internacional. Barcelona, GEXEL vol.1, 189-210.

SARTre, Jean-Paul. 1981. L'Être et le Néant. Paris, Gallimard.

SEMPrún, Jorge. 1963. Le grand voyage. Paris, Gallimard

Semprún, Jorge. 1998. Adieu, vive clarté. Paris, Gallimard. 
Anales de Filología Francesa, n. ${ }^{\circ}$ 28, 2020

Rita RodríGuez VARELA

Semprún, Jorge. 2003. "Entrevista con Jorge Semprún” in El País, Cultura. <https://elpais. com/cultura/2003/09/24/actualidad/1064405917_1064406916.html> [08/04/2020].

SteINER, George. 1973. Extraterritorial. Ensayos sobre literatura y revolución lingüística. Barcelona, Barral.

Vilanova, M. 2006. “Jorge Semprún, París 2005” in Historia, Antropología y Fuentes Orales, Utopía y Contrautopía, n³5, 105-117.

WeIL, Simone. 1949. L'enracinement. Paris, Gallimard.

ZaYAs, Rodrigo (De). 1996. La Brigue et le talion. Paris, L'Esprit des Péninsules.

Zimbris, Sandrine. 2010. La poésie et l'intimité ou L'identité et l'être au monde, vol. I, Université de Limoges. 
